\begin{tabular}{ll}
\hline & $\begin{array}{l}\text { Kastamonu Eğitim Dergisi } \\
\text { Kastamonu Education Journal }\end{array}$ \\
& $\begin{array}{l}\text { Eylül 2019 Cilt:27 Sayı:5 } \\
\text { kefdergi.kastamonu.edu.tr }\end{array}$ \\
\hline
\end{tabular}

\title{
Beşinci Sınıf Öğrencilerinin Isı ve Sıcaklıkla İlgili Kavram Yanılgılarının Belirlenmesinde Mektup Yazma Aktivitesinin Kullanılması ${ }^{1}$
}

\section{The Use Of Letter Writing Activity To Identify $5^{\text {th }}$ Grade Students' Misconceptions About Heat And Temperature}

\section{Öz}

\author{
Mustafa UZOĞLU², Fatih AKTÜRK ${ }^{3}$
}

Bu araştırmanın amacı, beşinci sınıf öğrencilerinin ısı ve sıcaklık konusundaki kavram yanılgılarını öğrenme amaçIı yazma aktivitelerinden mektup yazma ile belirlemektir. Araştırmada nitel araştırma yöntemlerinden doküman incelemesi kullanılmıştr. Araştırmanın örneklemini 2017-2018 eğitim-öğretim yılı güz döneminde Giresun Yağıdere'deki iki devlet ortaokulunda öğrenim görmekte olan beşinci sınıftan 50 öğrenci oluşturmuştur. Veri toplama aracı olarak öğrenme amaçlı yazma aktivitelerinden mektup yazma aktivitesi kullanılmıştr. Öğrencilerin yazmış oldukları mektuplar içerik analizi yöntemi ile analiz edilmiş, öğrencilerin verdikleri cevaplara uygun olarak tema ve kodlar oluşturularak tablolar oluşturulmuştur. Araştırmanın sonucunda beşinci sınıf öğrencilerinin ısı ve sıcaklıkla ilintili kavramlara ilişkin birçok eksik ya da kavram yanılgısına sahip oldukları sonucuna varılmıştır.

Anahtar Kelimeler: ısı, sıcaklık, kavram yanılgısı, öğrenme amaçlı yazma, mektup

\section{Abstract}

The purpose of this study to identify fifth grade students' misconceptions about heat and temperature through letter writing, one of the writing-to-learn activities. Document analysis, a qualitative research method, was used for this study. The sample of this study consisted 50 fifth graders from two middle schools in Yağlıdere, Giresun in 2017-2018 Fall Term. Letter writing, a writing-to-learn activity, was used as data collection method. The letters of the students were examined through content analysis and then tables were created by using themes and codes according to the students' replies. The results of this study concluded that the fifth graders had many missing conceptions and misconceptions about heat and temperature.

Keywords: heat, temperature, misconception, writing-to-learn, letter 


\section{Extended Abstract}

Introduction: Science learning must be treated as a kind of thinking strategy, not as a way of memorizing a number of facts, and it should be illuminating the willingness of children to make sense of the world. In this context, in order for science education to be effective, concepts based on human knowledge must be studied and examined (Topsakal, 2009).

Concepts are the initial associations of any object in the human mind (Çepni, 2005). Knowing the first information or concepts created in the minds has a great importance in learning the concepts of children. Identifying the first concepts that children have already had in important science subjects and which are also great influences in their learning constitutes the theme of a broad research field in science education (Griffiths, Thomey, Cooke and Normore, 1988).

The first concepts in the minds of the students are called "wrong" or "faulty" when they do not match accepted scientific concepts (YIlmaz, 1998). Misconceptions arise when students fail to achieve conceptual change in their minds throughout their learning, and they fail to provide meaningful completeness when learning concepts (Koray and Bal, 2002).

Misconceptions have been tried to be determined by many researchers using multiple choice questions (Khurshid and Iqbal, 2009). The use of multiple choice questions to measure misconceptions is a controversial issue. Uzoğlu and Gürbüz (2013) have demonstrated through their work that the letter writing activity for learning can use in determining the misconceptions.

The foundation of writing to learn is based on Emig. According to Emig (1977) writing to learn is an unusual and unique learning way. Writing to learn allows for long-lasting scientific knowledge and reinforces new ideas with previous knowledge (Rivard and Straw, 2000). In addition, writing to learn helps to teach more difficult-learned concepts (Hohenshell, Hand and Staker, 2004).

It was discovered in the work of Uzoğlu and Gürbüz (2013) that the letter writing activity for learning allows the students to write their thoughts in a freeway without limiting the ideas of the students as they are already in the multiple-choice questions, and in this respect, they can be used to determine the misconceptions. In this study, it is considered that letter writing activity can be used in writing activities for learning purposes at lower levels of the education levels, thus it is considered to be an effective method in determining the misconceptions in 5th-grade students.

Method: Phenomenological research method was used in this study.

The study group of this research was composed of 50 students studying in 5th-grade in two state secondary schools in Giresun Yağlıdere in autumn term a 2017-2018 academic year. Typical case sampling method was used to select the study group.

As a means of collecting data in the study, letter writing, which is the writing activity for learning purposes, was used in determining the misconceptions of the fifth-grade students in terms of heat and temperature.

The data of the study were analyzed by content analysis from qualitative analysis techniques. Content analysis is defined as a systematic, repeatable technique in which certain words of a text are summarized by smaller content categories with certain rules-based coding (Büyüköztürk, Çakmak, Akgün, Karadeniz ve Demirel, 2011).

Findings: The themes and codes were determined according to the answers in the letters written by the 5th-grade students and the tables were created. The total number of students and percentages are shown in the tables. When the tables are examined, it is seen that there are many sharing about the definition of heat, unit of heat, whether the heat can be measured, what is the heat measured by. Temperature definition, unit of temperature, whether the temperature can be measured, what is the temperature measured by. And the answers they have written show that they have many missing or misconceptions.

When the responses of the students written in letters about the definition of heat were analyzed, it was seen that some students associate with heat, energy and temperature themes. Students express heat as an energy source $(\% 2)$, energy flowing downward $(\% 2)$, temperature or cold of a material $(\% 2)$, boiling temperature of a material (\%2), and a temperature that transitions from one environment to another. These are some misconceptions that are derived from the findings of this research.

When the responses of the students about the unit of heat were analyzed, it was seen that some students have expressed the unit of heat as ${ }^{\circ} \mathrm{C}$, degrees Celsius $\left({ }^{\circ} \mathrm{C}\right)(\% 6)$, joe (co) (\%2), C (\%2), jul or selsiyus (\%2), kilometers $(\% 2)$, degree $\left({ }^{\circ}\right)(\% 2)$, kınoni (\%2) and they have misconceptions.

When the responses of the students about whether heat can be measured were analyzed, some of the students (\%10) expressed their thoughts as non-heat-measurable. This indicates that students have misconceptions.

When the answers to what the students wrote about how the heat was measured in the letters were analyzed, some of the misconceptions about this question are that the students' heat is measured with a thermometer 
$(14 \%)$, measured with a thermometer container (\%6), measured with a heated container (\%2).

When the responses of the students written in letters about the definition of temperature were analyzed, it was seen that some students associate with temperature, energy, heat, magnitude and measurement themes. Students express temperature as an energy (\%6), heat-like (\%2), heat and temperature are concepts close to each other (\%2), the magnitude passed from one material to another and a measurement. These are some misconceptions that are derived from the findings of this research.

When the responses of the students about the unit of temperature were analyzed, it was seen that some students have expressed the unit of temperature as calori (\%2), juul (\%2), cal (\%2), j (\%2), jol (\%2), joe (co) (\%2), calori veya jul (\%2), newton (\%2) and they have misconceptions.

When the responses of the students about whether temperature can be measured were analyzed, some of the students (\%4) expressed their thoughts as non-temperature-measurable. This suggests that students have misconceptions.

When the responses of the students about what the temperature is measured in the letters are analyzed, some of the misconceptions about this question are that students should measure the temperature with a dynamometer (\%4), a calorimeter (\%2), and a temperature probe (\%2).

Discussion, Result and Recommendations: When the literature is examined, it is noteworthy that multiple-choice tests have been extensively used to detect misconceptions (Khurshid and Iqbal, 2009). The use of multiple-choice tests for this purpose is being discussed by researchers (Eryılmaz ve Sürmeli, 2002). In this study, it was revealed that the letter writing activity for learning could be used to determine the misconceptions. In this study, it was determined that students' conceptual knowledge about heat and temperature were weak, and they had misconceptions. This situation is similar to that obtained in many studies (Akgül, 2010; Aydın, 2007; Aydoğan, Güneş ve Gülçiçek, 2003; Bayram, 2010; Demirci ve Sarıkaya, 2004; Duman ve Avcı, 2016; Erickson, 1979; 1980; Erkaçan, Moğol ve Ünsal, 2012; Eryılmaz ve Sürmeli, 2002; Gönen ve Akgün, 2005; Kaptan ve Korkmaz, 2001; Karakuyu, 2006; Karamustafaoğlu, Özmen ve Ayvacı, 2004; Kesidou ve Duit, 1993; Kırıkkaya ve Güllü, 2008; Uzoğlu ve Gürbüz, 2013).

When the results obtained from the study were taken into account, it was concluded that middle school 5th-grade students had many incomplete or misconceptions about the concepts related to heat and temperature.

It should be taken into consideration that the concepts in the first and second grades of primary education are very difficult to structure correctly in the mind, but also very important. The effect of effort that teachers show in the solution of this situation is great. Teachers should follow innovations by keeping up with the era and opt out of customary methods and special events and methods to avoid misconceptions. In this respect, it should not be thought that the education received before the teachers started to work is sufficient, and the importance of subject about concept teaching and misconceptions with in-service training should be understood. 


\section{Giriş}

Teknolojinin hızla ilerlediği, bilimsel gelişmelerin her geçen gün artarak devam ettiği günümüz dünyasında bilimsel anlamda saygın bir yere ulaşabilmek ve toplumun intiyaçlarını karşılayabilmek için fen eğitimi üzerinde önemle durulması gerekir. Bu kapsamda Topsakal (2009), fen öğreniminin çocukların bir takım gerçekleri ezberlemesi tarzında değil, bir tür düşünme stratejisi şeklinde ele alınması ve çocukların dünyayı anlamlandırma isteklerini aydınlatıcı nitelikte olması gerektiğini ifade etmiştir. Ayrıca fen eğitiminin etkili olabilmesi için, insana ait olan bilgilerin temelindeki kavramlar ele alınarak incelenmesine vurgu yapmıştır.

Kavramlar, herhangi bir nesnenin insan zihninde oluşturduğu ilk çağrışımlardır (Çepni, 2005). Zihinlerde oluşturulan ilk bilgilerin diğer bir ifadeyle kavramların bilinmesi çocukların kavramları öğrenmesinde büyük bir öneme sahiptir. Çocukların önemli fen konularında önceden sahip oldukları ve öğrenmelerine de büyük etkisi olan ilk kavramların belirlenmesi, fen eğitiminde geniş bir araştırma alanının konusunu oluşturur (Griffiths, Thomey, Cooke ve Normore, 1988).

Öğrencilerin zihinlerindeki ilk kavramlar, kabul edilmiş bilimsel kavramlarla uyuşmadığında "yanlış" veya "hatalı" olarak adlandırılırlar (Yılmaz, 1998). Kavram yanılgıları örgün eğitim sürecinde de ortaya çıkabilir. Örneğin bilimsel kavramların öğretmenler tarafindan okullarda hatalı öğretilmesi ya da öğrenciler tarafindan hatalı bir şekilde öğrenilmesi ile kavram yanılgıları oluşabilir. Ayrıca öğrenciler, ilk defa öğrendikleri bir konuda sahip oldukları ön bilgilerini kullanmada yetersiz kalmış olabilir. Kavram yanılgıları, öğrencilerin öğrenmeleri boyunca zihinlerindeki kavramsal değişimi sağlamada başarısız oldukları ve kavramların öğrenilmesinde anlam bütünlüğünü sağlayamadıklarında ortaya çıkar (Koray ve Bal, 2002).

Fen eğitimi literatürüne bakıldığında kavram yanılgılarının belirlenmesi için birçok araştırmanın olduğu, yapılan araştrrmalar incelendiğinde ısı ve sıcaklık konusunun sıklıkla ele alındığı görülmektedir (Akgül, 2010; Aydın, 2007; Aydoğan, Güneş ve Gülçiçek, 2003; Aytekin, 2010; Başer ve Çataloğlu, 2005; Bayram, 2010; Demirci ve Sarıkaya, 2004; Duman ve Avcl, 2016; Erickson, 1979; 1980; Erkaçan, Moğol ve Ünsal, 2012; Eryılmaz ve Sürmeli, 2002; Gönen ve Akgün, 2005; Kaptan ve Korkmaz, 2001; Karakuyu, 2006; Karamustafaoğlu, Özmen ve Ayvacı, 2004; Keser, 2007; Kesidou ve Duit, 1993; Kırıkkaya ve Güllü, 2008; Kocaküllah ve Kocaküllah, 2002; Ongun, 2006; Özkan ve Azar, 2005; Uzoğlu ve Gürbüz, 2013; Yumuşak, 2008).

Isı ve sıcaklık konusunda ilgili literatür taranarak öğrencilerin sahip olduğu bazı kavram yanılgıları aşağıda listelenmiştir.

1. Isı ile sıcaklık aynı kavramdır (Akgül, 2010; Aydoğan, Güneş ve Gülçiçek, 2003; Duman ve Avcı, 2016; Erickson, 1979; 1980; Eryılmaz ve Sürmeli, 2002; Gönen ve Akgün, 2005; Kaptan ve Korkmaz, 2001; Karakuyu, 2006; Karamustafaoğlu, Özmen ve Ayvacı, 2004; Uzoğlu ve Gürbüz, 2013).

2. Isı termometre ile ölçülür (Aydın, 2007; Bayram, 2010; Demirci ve Sarıkaya, 2004; Erkaçan, Moğol ve Ünsal, 2012; Gönen ve Akgün, 2005; Kırıkkaya ve Güllü, 2008).

3. Isı bir enerji çeşidi değildir (Kırıkkaya ve Güllü, 2008).

4. Sıcaklık kalorimetre ile ölçülür (Kırıkkaya ve Güllü, 2008).

5. Isı ölçülemez (Kırıkkaya ve Güllü, 2008).

6. Sıcaklık bir maddeden diğer maddeye geçer (Kesidou ve Duit, 1993).

7. Isı, sıcaklık değişiminin birimidir (Aydın, 2007; Aydoğan, Güneş ve Gülçiçek, 2003; Aytekin, 2010; Bayram, 2010; Kırıkkaya ve Güllü, 2008; Kocaküllah ve Kocaküllah, 2002; Özkan ve Azar, 2005).

8. Isı maddenin ortalama kinetik enerjisidir (Aydın, 2007; Aydoğan, Güneş ve Gülçiçek, 2003; Aytekin, 2010; Başer ve Çataloğlu, 2005; Bayram, 2010; Karakuyu, 2006; Karamustafaoğlu, Özmen ve Ayvacı, 2004).

9. Sıcaklık maddenin cinsine bağlıdır (Aydın, 2007; Bayram, 2010; Eryılmaz ve Sürmeli, 2002; Gönen ve Akgün, 2005; Karakuyu, 2006; Karamustafaoğlu, Özmen ve Ayvacı, 2004; Keser, 2007; Ongun, 2006).

10. Isı ve sıcaklığı ölçen aletler aynıdır (Akgül, 2010; Aydın, 2007; Başer ve Çataloğlu, 2005; Bayram, 2010; Gönen ve Akgün, 2005; Kırıkkaya ve Güllü, 2008; Yumuşak, 2008).

Kavram yanılgıları birçok araştırmacı tarafindan çoktan seçmeli sorular kullanılarak belirlenmeye çalışılmıştı (Khurshid ve Iqbal, 2009). Kavram yanılgılarını ölçmede çoktan seçmeli soruların kullanılmasının tartı̧ılan bir konu olduğu, kavram yanılgılarını belirlemede öğrenme amaçlı mektup yazma aktivitesinin kullanılabileceği Uzoğlu ve Gürbüz 
(2013)'ün yaptıkları çalışma ile ortaya çıkarılmıştır.

Öğrenme amaçlı yazmanın temelleri Emig'e dayanmaktadır. Öğrenme amaçlı yazma Emig (1977)'e göre sıra dışı ve eşsiz bir öğrenme yoludur. Öğrenme amaçlı yazma, bilimsel bilgilerin uzun süre kalıcı olmasını ve önceki bilgilerle yeni fikirlerin güçlendirilmesini sağlar (Rivard ve Straw, 2000). Bunun yanında öğrenme amaçlı yazma, daha güç öğrenilen kavramların öğretilmesine yardımda bulunur (Hohenshell, Hand ve Staker, 2004). Günel, Hand ve Gündüz (2006)'ün araştırmasındaki sonuca göre bilimsel konularla alakalı öğrenme amaçlı yazma, kavramların öğrenilmesinde öğrencilere yardımda bulunduğu düşüncesini desteklemektedir.

Öğrenme amaçı mektup yazma aktivitesinin öğrencilerin düşüncelerini çoktan seçmeli sorulardaki gibi sınırlamayarak özgür bir şekilde rahatça ifade ederek yazabilmelerine olanak sağladığı literatürdeki bazı çalışmalar tarafindan belirlenmiştir (Uzoğlu ve Gürbüz, 2013). Bu çalışmanın amacı mektup yazma aktivitesi kullanılarak beşinci sınıf öğrencilerinin ısı ve sıcaklık kavramları hakkındaki kavram yanılgılarını belirlemektir.

\section{Yöntem}

Çalışmada nitel araştrma yöntemlerinden olgu bilim yöntemi kullanılmıştır. Nitel araştırma türleri araştırma etkinliklerinin amaca uygun bir biçimde ve birbiriyle tutarlı olması açısından araştırmaya rehberlik eder. Olgubilim araştırmalarında veri analizinde verinin kavramsallaştırıması ve olguyu tanımlayabilecek temaların ortaya çıkarılması çabası vardır. Sonuçlar betimsel bir anlatım ile sunulur ve sık sık doğrudan alıntılara yer verilir. Bunun yanında ortaya çıkan temalar ve örüntüler çerçevesinde elde edilen bulgular açıklanır ve yorumlanır (Yıldırım ve Şimşek, 2008).

\section{Çalışma Grubu}

Bu araştırmadaki çalışma grubunu 2017-2018 eğitim-öğretim yılında güz dönemindeki Giresun Yağlıdere'de iki devlet ortaokulunda beşinci sınıfta okuyan 50 öğrenci oluşturmuştur. Çalışma grubu seçilirken amaçsal örnekleme yönteminden olan tipik durum örnekleme yöntemi kullanılmıştır. Amaçsal örnekleme olasılığı ve seçkisiz olmayan bir örnekleme yaklaşımıdır. Amaçsal örnekleme çalışmanın amacına bağlı olarak bilgi açısından zengin durumların seçilerek derinlemesine araştırma yapılmasına olanak tanır (Büyüköztürk, Çakmak, Akgün, Karadeniz ve Demirel, 2011).

\section{Veri Toplama Aracı}

Çalışmada veri toplama aracı olarak beşinci sınıf öğrencilerinin ısı ve sıcaklık konusundaki kavram yanılgılarının belirlenmesinde öğrenme amaçlı yazma aktivitesi olan mektup yazma kullanılmıştı. Öğrencilerden yönergedeki (Ek1) gibi muhatabına (aynı sınıf düzeyindeki bir arkadaşına) ısı ve sıcaklık konusundaki birtakım soruları cevaplayarak mektup yazmaları istenmiştir. Fen bilgisi eğitimi alanında uzman bir öğretim üyesi ve fen bilimleri öğretmenliği yapan iki öğretmen tarafindan yönerge incelenmiş ve onların görüşleri doğrultusunda sorular üzerinde değişikliklere gidilmiştir. Öğrencilerin yazdığı mektuplar öğrencilerdeki ısı ve sıcaklıkla ilgili kavram yanılgılarını belirlemede kullanılmıştır.

\section{Verilerin Analizi}

Çalışmanın verileri nitel analiz tekniklerinden içerik analizi ile değerlendirilmiştir. İçerik analizi, belirli kurallara dayalı kodlamalarla, bir metnin bazı sözcüklerinin daha küçük içerik kategorileri ile özetlendiği sistematik, yinelenebilir bir teknik olarak tanımlanmaktadır (Büyüköztürk, Çakmak, Akgün, Karadeniz ve Demirel, 2011). Mektupların analizinde ISı ve sıcaklık ile ilgili öğrencilerin paylaşmış olduğu bilgiler Fen Bilgisi Eğitimi alanında uzman bir öğretim üyesi, Fen Bilimleri öğretmenliği yapan iki öğretmen ve araştırmacı tarafindan analiz edilmiş olup aralarındaki görüş birliği oranının \%90'nın üzerinde olduğu belirlenmiştir. Görüş birliğine dayalı tema ve kodlar oluşturularak veriler tablolarda frekans (f) ve yüzde (\%) şeklinde gösterilmiştir.

\section{Bulgular ve Yorum}

Isının tanımı hakkında beşinci sınıf öğrencilerinin yazdıkları mektuplar analiz edilip değerlendirildiğinde, öğrencilerin ısı kavramı ile ilgili birçok kavram yanılgılarının olduğu tespit edilmiştir.

Öğrencilerin ısı kavramı ile ilgili olarak paylaşımları Tablo 1'de özetlenmiştir. 
Tablo 1. Isının tanımı ile ilgili analiz sonuçları, toplam öğrenci sayıları (f) ve yüzdeleri (\%)

\begin{tabular}{|c|c|c|c|}
\hline TEMA & KOD & FREKANS & YÜZDE \\
\hline \multirow{7}{*}{ ENERJi } & Isı, yüksek sıcaklıktan düşük sıcaklığa akan enerjidir. & 7 & 14 \\
\hline & $\begin{array}{l}\text { Isı, iki ortam arasındaki sıcaklık farkı nedeniyle yüksek sıcaklıktan düşük sıcaklığa geçiş ya- } \\
\text { pan bir enerji türüdür. }\end{array}$ & 1 & 2 \\
\hline & Isı, bir enerjidir. & 4 & 8 \\
\hline & Isı, bir enerji kaynağıdır. & 1 & 2 \\
\hline & Isı, bir enerji değildir. & 1 & 2 \\
\hline & Isı, sıcaktan aşağıya doğru akan enerjidir. & 1 & 2 \\
\hline & Isı, düşük sıcaklıktan yüksek sıcaklığa geçen enerji çeşididir. & 1 & 2 \\
\hline \multirow{15}{*}{ SICAKLIK } & Yüksekten alçak sıcaklığa ısı denir. & 1 & 2 \\
\hline & Isı, bir maddenin sıcaklığı veya soğukluğudur. & 1 & 2 \\
\hline & Isı demek bir şeyin ısısı demek bir şeyin sıcaklığıdır. & 1 & 2 \\
\hline & Isı, maddenin son yani kaynama sıcaklığıdır. & 1 & 2 \\
\hline & Isı, sıcaklığın tam tersidir. & 1 & 2 \\
\hline & Isı, sıcak bir şeydir. & 1 & 2 \\
\hline & Isı, sıcaklık ve soğukluk arasında bulunan bir nokta gibidir. & 1 & 2 \\
\hline & Isı, belirli sıcaklıkta oluşur her sıcaklıkta değil. & 1 & 2 \\
\hline & Isı, bir ortamdan diğer bir ortama geçiş yapan bir sıcaklıktır. & 1 & 2 \\
\hline & Isı, belirli bir sıcaklıktan düşüş yapan ve sabit kalan sıcaklığa denir. & 1 & 2 \\
\hline & Isı, her sıcaklıkta olan bir şeydir. & 1 & 2 \\
\hline & Isı, sıcak bir maddeden soğuk hale geçmesidir. & 1 & 2 \\
\hline & Isı, sıcaktan soğuğa akar. & 1 & 2 \\
\hline & Isı, bir şeyin çok sıcakta kaldığı zaman çok ısı olduğudur. & 1 & 2 \\
\hline & Isı, bizim sıcak olmamız için vücudumuz aracılığı ile bizim sıcak olmamızı sağlar. & 1 & 2 \\
\hline \multirow{9}{*}{ DiĞER } & Evin kapısını açtı̆ımızda ısı kapıya çıkar. & 1 & 2 \\
\hline & Isı, bir nesnede bulunan kalori miktarıdır. & 1 & 2 \\
\hline & Isı, her yerde vardır mesela dışarı çıktığımızda vardır. & 1 & 2 \\
\hline & Isı, diğer bir madde ile geçen alışveriştir. & 1 & 2 \\
\hline & IsI, bir ortamdan diğer ortama geçince değişir. & 1 & 2 \\
\hline & Isı, çok önemlidir. & 1 & 2 \\
\hline & Isı, Güneş ışığından gelen dalgaların dünyaya ulaşmasıdır. & 1 & 2 \\
\hline & Isı, bir büyüklüktür. & 1 & 2 \\
\hline & Isı, güneşten gelen dünyaya geldiğinde bize nesneleri görmemizi sağlayan ışık çeşididir. & 1 & 2 \\
\hline \multirow{6}{*}{ DiĞER } & Isı, iki ortamın ısı alışverişi yapmasıdır. & 1 & 2 \\
\hline & Isı eşitlenene kadar ısı alışverişi devam eder. & 1 & 2 \\
\hline & Bir maddenin Isı şeklidir. & 1 & 2 \\
\hline & Isı, bir maddeyle diğer bir madde arasında akar. & 1 & 2 \\
\hline & İki tane kabın ısısını ölçerek ısı olduğunu anlarız. & 1 & 2 \\
\hline & Paylaşımda bulunmayanlar & 5 & 10 \\
\hline
\end{tabular}

Tablo 1'e bakıldığında ısının tanımı hakkındaki düşüncelerin geniş bir alana yayıldığı görülmektedir. Uygulama yapılan öğrenciler ısıyı, yüksek sıcaklıktan düşük sıcaklığa akan enerji (\%14), iki ortam arasındaki sıcaklık farkı nedeniyle yüksek sıcaklıktan düşük sıcaklığa geçiş yapan bir enerji türü (\%2), bir enerji (\%8) gibi düşüncelerle doğru bir şekilde ifade etmişlerdir. Öğrencilerden bazıları ısıyı, bir enerji kaynă̆ı (\%2), bir enerji değil (\%2), sıcaktan aşağıya doğru akan enerji (\%2), düşük sıcaklıktan yüksek sıcaklığa geçen enerji çeşidi (\%2) şeklinde enerji ile ilişkilendirerek kavram yanılgılarının olduğu görülmektedir. Öğrencilerden \%30’u ısıyı sıcaklıkla ilişkilendirerek tanımlamaya çalışmış olup kavram yanılgılarına sahip olduğu Tablo 1'de görülmektedir. Bu öğrencilerin ısı hakkındaki sıcaklığın tam tersi (\%2), sıcak bir şey (\%2), maddenin son yani kaynama sıcaklığı (\%2), bir ortamdan diğer bir ortama geçiş yapan bir sıcaklık (\%2), belirli bir sıcaklıktan düşüş yapan ve sabit kalan sıcaklık (\%2) şeklindeki ifadeleri sıcaklıkla ilişkilendirilen kavram yanılgılarından bazılarıdır. Yine Tablo 1'e bakıldığında öğrencilerin \%28'i ısıyı diğer ifadelerle tanımlayarak kavram yanılgılarının oluşmasına sebep olmuşlardır. Ayrıca ısı kavramı hakkında paylaşımda bulunmayan (\%10) öğrenciler de vardır.

Beşinci sınıf öğrencilerinin yazdıkları mektuplar analiz edilip değerlendirildiğinde, öğrencilerin ısının birimi ile ilgili kavram yanılgılarının olduğu görülür. 
Öğrencilerin ısının birimi ile ilgili olarak paylaşımları Tablo 2'de özetlenmiştir.

Tablo 2. Isının birimi ile ilgili analiz sonuçları, toplam öğrenci sayıları (f) ve yüzdeleri (\%)

\begin{tabular}{llcc}
\hline TEMA & KOD & FREKANS & YÜZDE \\
\hline & Isının birimi joule'dür (J). & 11 & 22 \\
& Isının birimi kalori (cal) dir. & 9 & 18 \\
& Isının birimi joule $(\mathrm{J})$ ya da kalori (cal) dir. & 13 & 26 \\
& Isının birimi ${ }^{\circ} \mathrm{C}$ dir. & 3 & 6 \\
& Isının birimi derece selsiyus $\left({ }^{\circ} \mathrm{C}\right)^{\prime}$ tur. & 3 & 6 \\
BíRiM & Isının birimi joe (co)'dur. & 1 & 2 \\
& Isının birimi C'dir. & 1 & 2 \\
& Isının birimi jul ya da selsiyustur. & 1 & 2 \\
& Isının birimi kilometredir. & 1 & 2 \\
& Isının birimi derece $\left({ }^{\circ}\right)$ 'dir. & 1 & 2 \\
& Isının birimi kınonidir. & 1 & 2 \\
\hline DiĞER & Paylaşımda bulunmayanlar & 5 & 10 \\
\hline
\end{tabular}

Tablo 2'ye bakıldığında ısının birimi hakkında öğrencilerin düşünceleri görülmektedir. Öğrencilerin paylaşımlarına bakıldığında; ısının birimi joule'dür (\%22), ısının birimi kalori (cal) dir (\%18), ısının birimi joule (J) ya da kalori (cal) dir (\%26) şeklinde doğru ifade eden toplam öğrencilerin \%66'।ık bir orana sahip olduğu belirlenmiştir. Tablo 2 'ye bakıldığında bazı öğrencilerin ısının birimini ${ }^{\circ} \mathrm{C}(\% 6)$, derece selsiyus $\left({ }^{\circ} \mathrm{C}\right)(\% 6)$, joe (co) $(\% 2)$, C (\%2), jul ya da selsiyus (\%2), kilometre $(\% 2)$, derece $\left({ }^{\circ}\right)(\% 2)$, kınoni $(\% 2)$ olarak ifade ettikleri ve kavram yanılgılarına sahip oldukları görülmektedir. Ayrıca ısının birimi hakkında paylaşımda bulunmayan (\%10) öğrenciler de bulunmaktadır.

Isı ölçülebilir mi? sorusuna beşinci sınıf öğrencilerinin vermiş oldukları cevaplar analiz edilip değerlendirildiğinde, öğrencilerin bazılarında ısının ölçülüp ölçülmediğine dair kavram yanılgılarının olduğu tespit edilmiştir.

Öğrencilerin ısı ölçülebilir mi? sorusu ile ilgili olarak paylaşımları Tablo 3'de özetlenmiştir.

Tablo 3. Isı ölçülebilir mi sorusu analiz sonuçları, toplam öğrenci sayıları (f) ve yüzdeleri (\%)

\begin{tabular}{lcc}
\hline & FREKANS & YÜZDE \\
\hline EVET & 44 & 88 \\
HAYIR & 5 & 10 \\
DIĞER & 1 & 2 \\
\hline
\end{tabular}

Tablo 3'e bakıldığında ısının ölçüldüğünü doğru bir şekilde ifade eden öğrencilerin oranının \%88 olduğu görülmektedir. Öğrencilerin \%10'u ISI ölçülmez şeklinde düşüncelerini ifade etmişler ve bu öğrencilerin kavram yanılgılarının olduğu belirlenmiştir. Ayrıca ısı ölçülebilir mi sorusu ile ilgili paylaşımda bulunmayan öğrencilerin oranı $\% 2$ 'dir.

Isı ölçülürse neyle ölçülür sorusuna beşinci sınıf öğrencilerinin vermiş oldukları cevaplar analiz edilip değerlendirildiğinde, öğrencilerin ısının neyle ölçüldüğüne dair birtakım kavram yanılgılarının olduğu tespit edilmiştir.

Öğrencilerin ısı ölçülürse neyle ölçülür sorusu ile ilgili olarak paylaşımları Tablo 4'de özetlenmiştir.

Tablo 4'e bakıldığında ısının kalorimetre kabı ile ölçüldüğünü doğru bir şekilde ifade eden öğrencilerin oranı \%46 olarak belirlenmiştir. Isıyı öğrencilerin \%14'ü termometre ile ölçülür, \%6'sı termometre kabı ile ölçülür, \%2'si derece selsiyus kabı ölçülür, \%2'si ısı kabı ile ölçülür, \%2'si dinamo kabı ile ölçülür, \%2'si dereceli kap ile ölçülür, \%2'si kalibrato kabı ile ölçülür, \%2'si derece ile ölçülür, \%2'si kronometre ile ölçülür, \%2'si ısı ölçer ile ölçülür şeklinde ifade etmişler ve bu öğrencilerin kavram yanılgılarının olduğu belirlenmiştir. Ayrıca ısı ölçülürse neyle ölçülür sorusu ile ilgili paylaşımda bulunmayan öğrencilerin oranı \%18'dir. 
Tablo 4. Isı ölçülürse neyle ölçülür sorusu ile ilgili analiz sonuçları, toplam öğrenci sayıları (f) ve yüzdeleri (\%)

\begin{tabular}{llcc}
\hline TEMA & KOD & FREKANS & YÜZDE \\
\hline \multirow{2}{*}{ Isı kalorimetre kabı ile ölçülür. } & 23 & 46 \\
& Isı termometre ile ölçülür. & 7 & 14 \\
& Isı termometre kabı ile ölçülür. & 3 & 6 \\
& Isı derece selsiyus kabı ile ölçülür. & 1 & 2 \\
ISI & Isı, Isı kabı ile ölçülür. & 1 & 2 \\
& Isı dinamo kabı ile ölçülür. & 1 & 2 \\
& Isı dereceli kap ile ölçülür. & 1 & 2 \\
& Isı kalibrato kabı ile ölçülür. & 1 & 2 \\
& Isı derece ile ölçülür. & 1 & 2 \\
& Isı kronometre ile ölçülür. & 1 & 2 \\
\hline DiĞER & Isı ısı ölçer ile ölçülür. & 1 & 2 \\
\hline
\end{tabular}

Sıcaklığın tanımı hakkında beşinci sınıf öğrencilerinin yazdıkları mektuplar analiz edilip değerlendirildiğinde, öğrencilerin sıcaklık kavramı ile ilgili birçok kavram yanılgılarının olduğu tespit edilmiştir.

Öğrencilerin sıcaklık kavramı ile ilgili olarak paylaşımları Tablo 5'de özetlenmiştir.

Tablo 5. Sıcaklığın tanımı ile ilgili analiz sonuçları, toplam öğrenci sayıları (f) ve yüzdeleri (\%)

\begin{tabular}{|c|c|c|c|}
\hline TEMA & KOD & FREKANS & YÜZDE \\
\hline \multirow{5}{*}{ ENERJI } & Sıcaklık, bir enerjidir. & 3 & 6 \\
\hline & Sıcaklık, enerji çeşidi değildir. & 5 & 10 \\
\hline & Sıcaklık, yüksek sıcaklıktan belirli bir sıcaklığa doğru akan enerjidir. & 1 & 2 \\
\hline & Sıcaklık, enerji kaynağı değildir. & 1 & 2 \\
\hline & $\begin{array}{l}\text { Sıcaklık, enerji çeşidi olmayan maddenin belirli bir sıcaklıktan düşük bir sıcaklığa düşen } \\
\text { bir çeşittir. }\end{array}$ & 1 & 2 \\
\hline \multirow{5}{*}{ ISI } & Sıcaklık, ısıdan daha kuvvetli bir şeydir. & 1 & 2 \\
\hline & Isısı aşırı yüksek olan ısıya sıcaklık denir. & 1 & 2 \\
\hline & Sıcaklık, bir maddenin ısı olduğudur. & 1 & 2 \\
\hline & Sıcaklık, ısıya benzer. & 1 & 2 \\
\hline & Sıcaklık ve ısı birbirine yakın kavramlardır. & 1 & 2 \\
\hline \multirow{5}{*}{ BÜYÜKLÜK } & $\begin{array}{l}\text { Sıcaklık, bir maddenin diğer bir maddeye göre ne kadar sıcak veya ne kadar soğuk oldu- } \\
\text { ğunu gösteren büyüklüktür. }\end{array}$ & 6 & 12 \\
\hline & Sıcaklık, bir maddenin diğer bir maddeye bağlı olmasına büyüklük denir. & 1 & 2 \\
\hline & Sıcaklık, bir maddeden diğer maddeye geçen büyüklüktür. & 1 & 2 \\
\hline & Sıcaklık, küçük ısı ile büyük ısı arasında değişen büyüklüktür. & 1 & 2 \\
\hline & Sıcaklık, büyük sıcaklıktan küçük sıcaklığa akan büyüklüktür. & 1 & 2 \\
\hline \multirow[b]{2}{*}{ ÖLÇÜM } & $\begin{array}{l}\text { Sıcaklık, bir ortamdan bir ortama değişen ne kadar sıcak veya ne kadar soğuk olduğunu } \\
\text { gösteren ölçümdür. }\end{array}$ & 1 & 2 \\
\hline & Sıcaklık, bir ölçümdür. & 1 & 2 \\
\hline \multirow{11}{*}{ DíĞER } & Sıcaklık, iki kabın biri soğuk biri sıcak olması sonra da iki kabın da sıcak olmasıdır. & 1 & 2 \\
\hline & Sıcaklık, bir ortamın yaydığı sıcaklık çoktan aza doğru düşmesidir. & 1 & 2 \\
\hline & Sıcaklık, yüksek sıcaklıktan düşük bir sıcaklığa geçmesine denir. & 1 & 2 \\
\hline & Sıcaklık, güneş ışığında gelen dalganın dünyayı sıcaklatmasıdır. & 1 & 2 \\
\hline & Sıcaklık, bazı nesneler ya da cisimler sayesinde bize ulaşır. & 1 & 2 \\
\hline & Sıcaklık hava durumunda kullanılır. & 1 & 2 \\
\hline & Sıcaklık bir ortamdaki durumdur. & 1 & 2 \\
\hline & Sıcaklığı güneşten alabiliriz başka evde yaktığımız sobalardan alabiliriz. & 1 & 2 \\
\hline & Sıcaklık, bir ortamda bulunan etrafi kaplayan etkiye denir. & 1 & 2 \\
\hline & Sıcaklık, bir şey veya bir yer çok sıcak olduğunda sıcaklık meydana gelir. & 1 & 2 \\
\hline & Sıcaklık güneş tarafindan alabiliriz. & 1 & 2 \\
\hline
\end{tabular}




\begin{tabular}{|c|c|c|c|}
\hline TEMA & KOD & FREKANS & YÜZDE \\
\hline \multirow{9}{*}{ DiĞER } & Sıcaklık bir maddenin sıcaklığa bağlıdır. & 1 & 2 \\
\hline & Sıcaklık, bir ortamın sıcak olup olmama durumudur. & 1 & 2 \\
\hline & $\begin{array}{l}\text { Sıcaklık, bizim soğuktan korunmamız için vücudumuz aracılığı ile bizim sıcak olmamızı } \\
\text { sağlar. }\end{array}$ & 1 & 2 \\
\hline & Sıcaklık, sürekli artan birimdir. & 1 & 2 \\
\hline & Sıcaklık, bir maddenin hacminin yüksek olmasıdır. & 1 & 2 \\
\hline & Sıcaklık, gözle görülmez hissedebiliriz. & 1 & 2 \\
\hline & Sıcaklık, evin sobasını yaktığımızda ev sıcaklığını alana kadar yanar. & 1 & 2 \\
\hline & Sıcaklık, yüksek derecedir. & 1 & 2 \\
\hline & Paylaşımda bulunmayanlar & 3 & 6 \\
\hline
\end{tabular}

Tablo 5’e bakıldığında sıcaklığın tanımı hakkındaki öğrenci düşüncelerinin geniş bir alana yayıldığı görülmektedir. Uygulama yapılan öğrenciler sıcaklığı, bir maddenin diğer bir maddeye göre ne kadar sıcak veya ne kadar soğuk olduğunu gösteren büyüklük (\%12), enerji çeşidi değildir (\%10) şeklinde doğru ifade ettikleri belirlenmiştir. Öğrencilerden bazıları sıcaklığı, bir enerjidir (\%6), yüksek sıcaklıktan belirli bir sıcaklığa doğru akan enerjidir (\%2), enerji kaynağı değildir (\%2), enerji çeşidi olmayan maddenin belirli bir sıcaklıktan düşük bir sıcaklığa düşen bir çeşittir (\%2) şeklinde enerji ile ilişkilendirmiş olup kavram yanılgılarının olduğu görülmektedir. Öğrencilerden bazıları ise sıcaklığı, ısıdan daha kuvvetli bir şeydir (\%2), ısısı aşırı yüksek olan ısıya denir (\%2), bir maddenin ısı olduğudur (\%2), ısıya benzer (\%2), sıcaklık ve ısı birbirine yakın kavramlardır (\%2) şeklinde ısı ile ilişkilendirerek tanımlamaya çalışmış olup kavram yanılgılarına sahip olduğu Tablo 5'de görülmektedir. Öğrencilerden \%8'i sıcaklığı büyüklükle ilişkilendirerek, bir maddenin diğer bir maddeye bağıı olmasına büyüklük denir (\%2), bir maddeden diğer maddeye geçen büyüklüktür (\%2), küçük ısı ile büyük ısı arasında değişen büyüklüktür (\%2), büyük sıcaklıktan küçük sıcaklığa akan büyüklüktür (\%2) şeklinde tanımlamış olup kavram yanılgılarının olduğu görülmektedir. Bazı öğrenciler (\%4) sıcaklığı ölçüm ile ilişkilendirerek, bir ortamdan bir ortama değişen ne kadar sıcak veya ne kadar soğuk olduğunu gösteren ölçümdür (\%2), bir ölçümdür (\%2) şeklinde tanımlayarak kavram yanılgıları oluşmasına sebep olmuşlardır. Yine Tablo 5'e bakıldığında öğrencilerin \%38'i sıcaklığı diğer tanımlarla eksik ya da yanlış ifade ederek kavram yanılgılarının oluşmasına sebep olmuşlardır. Ayrıca sıcaklık kavramı hakkında paylaşımda bulunmayan (\%6) öğrenciler de vardır.

Beşinci sınıf öğrencilerinin yazdıkları mektuplar analiz edilip değerlendirildiğinde, öğrencilerin sıcaklığın birimi ile ilgili kavram yanılgılarının olduğu söylenebilir.

Öğrencilerin sıcaklı̆ı̆n birimi ile ilgili olarak paylaşımları Tablo 6’da özetlenmiştir.

Tablo 6. Sıcaklığın birimi ile ilgili analiz sonuçları, toplam öğrenci sayıları (f) ve yüzdeleri (\%)

\begin{tabular}{llcc}
\hline TEMA & KOD & FREKANS & YÜZDE \\
\hline \multirow{4}{*}{ BíRiM } & Sıcaklığın birimi derece selsiyus $\left({ }^{\circ} \mathrm{C}\right)^{\prime}$ tur. & 29 & 58 \\
& Sıcaklığın birimi santigrat derecedir. & 5 & 10 \\
& Sıcaklığın birimi kaloridir. & 1 & 2 \\
& Sıcaklığın birimi juuldur. & 1 & 2 \\
& Sıcaklığın birimi cal'dir. & 1 & 2 \\
& Sıcaklığın birimi j'dir. & 1 & 2 \\
& Sıcaklığın birimi jol'dür. & 1 & 2 \\
& Sıcaklığın birimi joe (co)'dir. & 1 & 2 \\
\hline \multirow{3}{*}{ BíRiM } & Sıcaklığın birimi calori veya jul'dür. & 1 & 2 \\
& Sıcaklığın birimi newton'dur. & 1 & 2 \\
& Sıcaklığın birimi 0 'dır. & 1 & 2 \\
& Sıcaklığın birimi santigrat, derece veya joule'dür. & 1 & 2 \\
\hline DiĞER & Sıcaklığın birimi joul diye adlandırılır. & 1 & 2 \\
\hline
\end{tabular}

Tablo 6'ya bakıldığında sıcaklığın birimi hakkında öğrencilerin düşünceleri görülmektedir. Sıcaklığın birimini derece selsiyus $\left({ }^{\circ} \mathrm{C}\right)$ olarak doğru bir şekilde ifade eden öğrencilerin $\% 58^{\prime}$ lik bir orana sahip olduğu, santigrat derecedir olarak doğru bir şekilde ifade eden öğrencilerin ise \%10'luk bir orana sahip olduğu belirlenmiştir. Yine Tablo 6'ya bakıldığında 
bazı öğrencilerin sıcaklığın birimini kalori (\%2), juul (\%2), cal (\%2), j (\%2), jol (\%2), joe (co) (\%2), calori veya jul (\%2), newton (\%2), $0(\% 2)$, santigrat, derece veya joule (\%2), joul (\%2) olarak ifade ettikleri ve kavram yanılgılarına sahip oldukları görülmektedir. Ayrıca sıcaklığın birimi hakkında paylaşımda bulunmayan (\%10) öğrenciler de bulunmaktadır.

Sıcaklık ölçülebilir mi? sorusuna beşinci sınıf öğrencilerinin vermiş oldukları cevaplar analiz edilip değerlendirildiğinde, bazı öğrencilerde sıcaklığın ölçülüp ölçülmediğine dair kavram yanılgılarının olduğu tespit edilmiştir.

Öğrencilerin sıcaklık ölçülebilir mi sorusu ile ilgili olarak paylaşımları Tablo 7'de özetlenmiştir.

Tablo 7. Sıcaklık ölçülebilir mi sorusu analiz sonuçları, toplam öğrenci sayıları (f) ve yüzdeleri (\%)

\begin{tabular}{lcc}
\hline & FREKANS & YÜZDE \\
\hline EVET & 48 & 96 \\
HAYIR & 2 & 4 \\
\hline
\end{tabular}

Tablo 7’ye bakıldığında sıcaklığın ölçüldüğünü doğru bir şekilde ifade eden öğrencilerin oranının \%96 olduğu görülmektedir. Öğrencilerin \%4'ü sıcaklık ölçülmez şeklinde düşüncelerini ifade etmişler ve bu öğrencilerin kavram yanılgılarının olduğu belirlenmiştir.

Sıcaklık ölçülürse neyle ölçülür sorusuna beşinci sınıf öğrencilerinin vermiş oldukları cevaplar analiz edilip değerlendirildiğinde, öğrencilerde sıcaklığın neyle ölçüldüğüne dair birtakım kavram yanılgılarının olduğu tespit edilmiştir.

Öğrencilerin sıcaklık ölçülürse neyle ölçülür sorusu ile ilgili olarak paylaşımları Tablo 8'de özetlenmiştir.

Tablo 8. Sıcaklık ölçülürse neyle ölçülür sorusu ile ilgili analiz sonuçları, toplam öğrenci sayıları (f) ve yüzde (\%)

\begin{tabular}{llcc}
\hline TEMA & KOD & FREKANS & YÜZDE \\
\hline \multirow{6}{*}{ SICAKLıK } & Sıcaklık termometre ile ölçülür. & 41 & 82 \\
& Sıcaklık dinamometre ile ölçülür. & 2 & 4 \\
& Sıcaklık kılorimetre ile ölçülür. & 1 & 2 \\
& Sıcaklık kaloromi metre kabı ile ölçülür. & 1 & 2 \\
& Sıcaklık kalorimetre kabı ile ölçülür. & 1 & 2 \\
& Sıcaklık calorimetreyle ölçülür. & 1 & 2 \\
& Sıcaklık, sıcaklık kabı ile ölçülür. & 1 & 2 \\
\hline
\end{tabular}

Tablo 8'e bakıldığında sıcaklığın termometre ile ölçüldüğünü doğru bir şekilde ifade eden öğrencilerin oranı \%82 olarak belirlenmiştir. Öğrenciler sıcaklığı dinamometre ile (\%4), kılorimetre ile (\%2), kaloromi metre kabı ile (\%2), kalorimetre kabı ile (\%2), calorimetreyle (\%2), sıcaklık kabı ile (\%2) ölçülür şeklinde ifade etmiş ve bu da kavram yanılgılarının oluşmasına sebep olmuştur. Ayrıca sıcaklık ölçülürse neyle ölçülür sorusuna dair paylaşımda bulunmayan (\%4) öğrenciler de bulunmaktadır.

\section{Sonuç, Tartışma ve Öneriler}

Araştırmanın sonucunda ısı ve sıcaklık konusunda beşinci sınıf öğrencilerinin birçok eksik bilgilerinin ya da kavram yanılgılarının olduğu belirlenmiştir.

Öğrenme amaçlı yazma aktivitelerinin kullanıldığı çalışmalar ve araştırmalarda son yıllarda büyük bir artı̧ olduğu görülmektedir. Öğrenme amaçlı yazma aktivitelerinin öğrenci öğrenmelerine pozitif katkılar sağladığı, öğrencilerin iletişim becerilerini geliştirdiği, öğrenmeye farklı katkılar sağladığı pek çok çalışmaların sonuçlarıyla belirlenmiştir (Günel, Uzoğlu ve Büyükkasap, 2009; Hohenshell, Hand ve Staker, 2004; Tynjala, 1998; Uzoğlu ve Gürbüz, 2013). Yapılan bu çalışmayla da öğrenme amaçlı yazma aktivitelerinden mektup yazma kullanılarak ısı ve sıcaklık konusunda öğrencilerin çeşitli kavram yanılgıları belirlenerek fen öğrenimine katkıda bulunulduğu düşünülmektedir.

Literatüre bakıldığında kavram yanılgılarını tespit etmede daha çok çoktan seçmeli testlerin kullanıldığı ön plana çıkmaktadır (Khurshid ve Iqbal, 2009). Oysaki çoktan seçmeli testlerin bu amaçla kullanılması araştırmacılar tarafindan tartı̧ılmaktadır (Eryılmaz ve Sürmeli, 2002). Bu çalışmada öğrenme amaçlı mektup yazma aktivitesi kullanılarak öğrencilerin düşüncelerini rahatça ifade edebildiği ve kavram yanılgılarını belirlemeye yönelik kullanılabileceği görülmektedir. Bu çalışmada ısı ve sıcaklık konusunda öğrencilerin kavram bilgilerinin düşük olması ve kavram yanılgılarına sahip olma- 
ları birçok çalışmada da elde edilen verilerle benzerlik göstermektedir (Akgül, 2010; Aydın, 2007; Aydoğan, Güneş ve Gülçiçek, 2003; Bayram, 2010; Demirci ve Sarıkaya, 2004; Duman ve Avcı, 2016; Erickson, 1979; 1980; Erkaçan, Moğol ve Ünsal, 2012; Eryılmaz ve Sürmeli, 2002; Gönen ve Akgün, 2005; Kaptan ve Korkmaz, 2001; Karakuyu, 2006; Karamustafaoğlu, Özmen ve Ayvacı, 2004; Kesidou ve Duit, 1993; Kırıkkaya ve Güllü, 2008; Uzoğlu ve Gürbüz, 2013).

Çalışmanın bulgularından elde edilen sonuçlara bakıldığında, beşinci sınıf öğrencilerinin ısı ile sıcaklığı birbirine karıştırdığı, öğrencilerin ısı ile sıcaklık aynı kavramlardır ifadesi kavram yanılgısının olduğunu göstermekte olup birçok araştrmacı da benzer verileri elde etmiştir (Akgül, 2010; Aydoğan, Güneş ve Gülçiçek, 2003; Duman ve Avcı, 2016; Erickson, 1979; 1980; Eryılmaz ve Sürmeli, 2002; Gönen ve Akgün, 2005; Kaptan ve Korkmaz, 2001; Karakuyu, 2006; Karamustafaoğlu, Özmen ve Ayvacı, 2004; Uzoğlu ve Gürbüz, 2013). Çalışmanın başka bir sonucuna göre de beşinci sınıf öğrencilerinin termometreler ısıyı ölçer ifadesinin kavram yanılgısına sebep olduğu ve benzer sonuca başka araştırmacılar tarafindan da ulaşıldığı tespit edilmiştir (Aydın, 2007; Bayram, 2010; Demirci ve Sarıkaya, 2004; Erkaçan, Moğol ve Ünsal, 2012; Gönen ve Akgün, 2005; Kırıkkaya ve Güllü, 2008). Yine bu çalışmadan elde edilen beşinci sınıf öğrencilerinin ısı bir enerji çeşidi değildir, sıcaklık kalorimetreyle ölçülür ifadeleri kavram yanılgısı oluşturduğu, benzer sonuca Kırıkkaya ve Güllü (2008) yaptıkları çalışmayla ulaşmışlardır. Çalışmanın bulgularına bakıldığında beşinci sınıf öğrencilerinin ısının ölçülemediğini ifade etmesi kavram yanılgısı oluşturmuş olup benzer sonuca Kırıkkaya ve Güllü (2008) yaptıkları çalışmayla ulaşmışlardır. Çalışmadan elde edilen beşinci sınıf öğrencilerinin sıcaklık bir maddeden diğer maddeye geçer ifadesi kavram yanılgısına sebep olmuş, benzer sonuç Kesidou ve Duit (1993)'in araştırmasında da görülmektedir.

Çalışmanın bulgularından elde edilen sonuçlara bakıldığında uygulama yapılan beşinci sınıf öğrencilerinin ısı ve sıcaklıkla ilintili kavramlara ilişkin birçok eksik ya da kavram yanılgısına sahip oldukları sonucuna varılmıştı. Kavram yanılgılarını belirlemeye yönelik bu ve buna benzer çalışmalar yapılarak giderilmediği durumlarda bireylerin sonraki yaşantılarında da yanlış şekilde kullanılıp devam edebileceği düşünülmektedir.

İlk ve ortaokulda kavramların zihinde doğru bir şekilde yapılandırmasının oldukça zor ve önemli olduğu göz önünde bulundurulabilir. Bu durumun çözümünde öğretmenlerin gösterecekleri çabanın etkisi büyüktür. Öğretmenler çağa ayak uydurarak yenilikler takip edilebilir ve alışılmış yöntemlerin dışına çıkılarak kavram yanılgılarının oluşmaması için özel etkinlikler ve yöntemler tercih edilebilir. Bu konuda da öğretmenlerin mesleğe başlamadan önce aldığı eğitimin yeterli olduğu düşünülmeyerek, hizmet içi eğitimlerle kavram öğretimi ve kavram yanılgıları konusunda öğretmenlere konunun önemi kavratlabilir.

\section{Kaynakça}

Akgül, P. (2010). Üstkavramsal faaliyetlerle zenginleştirilmiş kavramsal değişim metinlerinin fen bilgisi öğretmen adaylarının "ISI ve sıcaklık" konusundaki kavramsal anlamalarına etkisi. Yayınlanmamış Yüksek Lisans Tezi. Gazi Üniversitesi, Ankara.

Aydın, Z. (2007). Isı ve sıcaklık konusunda rastlanan kavram yanılgıları ve bu kavram yanılgıların giderilmesinde kavram haritalarının kullanılması. Yayınlanmamış Yüksek Lisans Tezi. Yüzüncü Yıl Üniversitesi, Van.

Aydoğan, S., Güneş, B. ve Gülçiçek, Ç. (2003). Isı ve sıcaklık konusunda kavram yanılgıları. Gazi Üniversitesi Eğitim Fakültesi Dergisi, 23(2).

Aytekin, Ü. (2010). Ortaöğretim öğrencilerin ısI-sıcaklık konusundaki bilgilerin belirlenmesi ve bu bilgilerin günlük hayata uyarlama düzeyleri üzerine bir araştırma. Yayınlanmamış Yüksek Lisans Tezi. Gazi Üniversitesi, Ankara.

Başer, M. ve Çataloğlu, E. (2005). Kavram değişimi yöntemine dayalı öğretimin öğrencilerin ısı ve sıcaklık konusundaki "yanlış kavramlar"ının giderilmesindeki etkisi. Hacettepe Üniversitesi Eğitim Fakültesi Dergisi, 29, 43-52.

Bayram, A. (2010). Probleme dayalı öğrenme yönteminin ilköğretim 5. sınıf öğrencilerinin fen ve teknoloji dersi "Isı ve sıcaklık" konusunda sahip oldukları kavram yanılgılarını gidermede etkisi. Yayınlanmamış Yüksek Lisans Tezi. Selçuk Üniversitesi, Konya.

Büyüköztürk, Ş., Çakmak, E., Akgün, Ö. E., Karadeniz, Ş. ve Demirel, F. (2011). Bilimsel Araştırma Yöntemleri (10. Baskı). Ankara: Pegem A Yayıncilık.

Çepni, S. (2005). Kuramdan uygulamaya fen ve teknoloji (4. Baskı). Ankara: Pegem A Yayıncllık.

Demirci, M. P. ve Sarıkaya, M. (2004). Sınıf öğretmeni adaylarının ısı ve sıcaklık konusundaki kavram yanılgıları ve yanılgıların giderilmesinde yapısalcı kuramın etkisi. XIII. Ulusal Eğitim Bilimleri Kurultayı, İnönü Üniversitesi, Malatya.

Duman, M. Ş. ve Avcı, G. (2016). Sekizinci sınıf öğrencilerinin maddenin halleri ve ısı ünitesine yönelik kavram yanılgıları. Uşak Üniversitesi Eğitim Araşttrmaları Dergisi, 2(3), 129-165.

Emig, J. (1977). Writing as a mode of learning. College Composition and Communication, 28, 122-128.

Erickson, G. L. (1979). Children's conceptions of heat and temperature. Science Education, 63(2), 221-230.

Erickson, G. L. (1980). Children's viewpoints of heat: a second look. Science Education, 64(3), 323-336.

| Kastamonu Eğitim Dergisi, 27(5), 2019 | 
Erkaçan, İ., Moğol, S. ve Ünsal, Y. (2012). Çoklu zekâ kuramının lise 1. sınıf öğrencilerinin ısı-sıcaklık, genleşme ve sıkıştırılabilirlik konularındaki akademik başarılarına ve öğrenmenin kalıcılığına etkisi. Türk Fen Eğitimi Dergisi, 9(2), 65-78.

Eryılmaz, A. ve Sürmeli, E. (2002). Üç-aşamalı sorularla öğrencilerin ısı ve sıcaklık konularındaki kavram yanılgılarının ölçülmesi. V. Ulusal Fen Bilimleri ve Matematik Eğitim Kongresi, Orda Doğu Teknik Üniversitesi, Ankara.

Griffiths, A. K., Thomey, K., Cooke, B. ve Normore, G. (1988). Remediation of student-specific misconceptions relating to three science concepts. Journal of Research in Science Teaching, 25(9), 709-719.

Gönen, S ve Akgün, A. (2005). Isı ve sıcaklık kavramları arasındaki ilişki ile ilgili olarak geliştirilen çalışma yaprağının uygulanabilirliğinin incelenmesi. Elektronik Sosyal Bilimler Dergisi, 3(11), 92-106.

Günel, M., Hand, B. ve Gündüz, S. (2006). Comparing student understanding of quantum physics when embedding multimodal representations into two different writing formats: presentation format versus summary report format. Science Education, 90, 1092-1112.

Günel, M., Uzoğlu, M. ve Büyükkasap, E. (2009). Öğrenme amaçlı yazma aktivitelerinin kullanımının ilköğretim seviyesinde kuvvet konusunu öğrenmeye etkisi. Gazi Üniversitesi Eğitim Fakültesi Dergisi, 29 (1), 379-399.

Hohenshell, L., Hand, B. ve Staker, J. (2004). Promoting conceptual understanding of biotechnology: writing to a younger audience. The American Biology Teacher, 66(5), 333-338.

Kaptan, F. ve Korkmaz, H. (2001). Fen eğitiminde probleme dayalı öğrenme yaklaşımı. Hacettepe Üniversitesi Eğitim Fakültesi Dergisi, 20(20).

Karakuyu, Y. (2006). Lise ve dengi okul öğrencilerini ısı ve sıcaklık ile ilgili kavram yanılgılarının belirlenmesi. Yayınlanmamış Doktora Tezi. Süleyman Demirel Üniversitesi, Isparta.

Karamustafaoğlu, O., Özmen, H. ve Ayvacı, H. Ş. (2004). Isı ve sıcaklık kavramlarının öğrencilerin zihninde yapılanmasına yönelik bir örnek olay incelemesi. Ondokuz Mayıs Üniversitesi Eğitim Fakültesi Dergisi, 17(1), 105-117.

Keser, A. (2007). Afyonkarahisar il merkezindeki 9. sınıf öğrencilerinin ısı ve sıcaklık konusundaki kavram yanılgıları. Yayınlanmamış Yüksek Lisans Tezi. Kocatepe Üniversitesi, Afyon.

Kesidou, S. ve Duit, R. (1993). Students' conceptions of the second law of thermodynamics-an interpretive study. Journal of Research in Science Teaching, 30(1), 85-106.

Khurshid, M. ve Iqbal, M. Z. (2009). Children's misconceptions about units on changes, acids and laboratory preparation of co2. Bulletin of Education and Research, 31(2), 61-74.

Kırıkkaya, E. B. ve Güllü, D. (2008). İlköğretim beşinci sını öğrencilerinin ısı-sıcaklık ve buharlaşma-kaynama konularındaki kavram yanılgıları. ilkögretim Online, 7(1), 15-27.

Kocakülah, M. S. ve Kocakülah, A. (2002). İlköğretim fen eğitiminde yapılan deneysel çalışmalar ile ilgili öğretmen görüşleri. $V$. Ulusal Fen Bilimleri Ve Matematik Eğitimi Kongresi Bildirileri, Orta Doğu Teknik Üniversitesi, Ankara.

Koray, Ö. C. ve Bal, Ş. (2002). Fen öğretiminde kavram yanılgıları ve kavramsal değişim stratejisi. Kastamonu Eğitim Dergisi, 10(1), 83-90.

Ongun, E. (2006). Üniversite öğrencilerin ısı ve sıcaklık konusundaki kavram yanılgıları ile motivasyon ve bilişsel stilleri arasındaki ilişki. Yayınlanmamış Yüksek Lisans Tezi. Abant İzzet Baysal Üniversitesi, Bolu.

Özkan, M. ve Azar, A. (2005). Örnek olaya dayalı öğretim yönteminin dokuzuncu sınıf öğrencilerinin ders başarısı ve derse karşı tutumlarına olan etkisinin incelenmesi. Milli Eğitim Dergisi, 168.

Rivard, L. P. ve Straw, S. B. (2000). The effect of talk and writing on learning science: An exploratory study. Science Education, 84, 566-593.

Topsakal, Ü. U. (2009). Tematik öğretimin canlı ve cansız varlıklarla ilgili kavram yanılgılarının giderilmesinde etkililiği. Sakarya Üniversitesi Eğitim Fakültesi Dergisi, 17.

Tynjala, P. (1998). Writing as a tool for constructive learning: students' learning experiences during an experiment. Higher Education, 36, 209-230.

Uzoğlu, M. ve Gürbüz, F. (2013). Fen ve teknoloji öğretmen adaylarının ısı ve sıcaklık konusundaki kavram yanılgılarının belirlenmesinde öğrenme amaçlı mektup yazma aktivitesinin kullanılması. International Journal of Social Science, 4(6), 501-517.

Yıldırım, A. ve Şimşek, H. (2008). Sosyal bilimlerde nitel araştırma yöntemleri (6.Baskı). Ankara: Seçkin Yayıncılık.

Yılmaz, Ö. (1998). Kavramsal değişim metinleri ile verilen kavram haritalarının hücre bölünmesi ünitesini anlamadaki etkisi. Yayımlanmamış Yüksek Lisans Tezi. Orta Doğu Teknik Üniversitesi, Ankara.

Yumuşak, A. (2008). Fen bilgisi öğretmen adaylarının ısı-sıcaklık, mekanik ve elektrik konularındaki kavram yanılgıları ve nedenlerinin araştırılması. Milli Eğitim Dergisi, 180, 123-132. 
Ek1

Yönerge:

Beşinci sınıfa giden bir arkadaşınız ısı ve sıcaklık kavramları hakkında bilgi toplamaktadır. Bu konuda da sizin bilginizden faydalanmak istemektedir. Siz de bu konuda arkadaşınızın cevabını bulamadığı aşağıdaki sorularla ilgili ona detaylı bilgi içeren bir mektup yazmaya karar verdiniz.

Isıyı tanımlayarak ısı hakkında bilgi veriniz. Isının birimini yazınız. Isı ölçülebilir mi? Isı ölçülürse neyle ölçülür? Sıcaklığı tanımlayarak sıcaklık hakkında bilgi veriniz. Sıcaklığın birimini yazınız. Sıcaklık ölçülebilir mi? Sıcaklık ölçülürse neyle ölçülür? sorularıyla ilgili açıklamalar vaparak, örnekler vererek ve sebepler göstererek mektubunuzu yazınız. Not: Mektubunuzu, mektup yazma kurallarına uygun olarak beşinci sınıf öğrencisine yazdığınızı unutmayınız. 